\title{
Sticky situation: best practice to secure endotracheal tubes in the operating room
}

\author{
Adam Davies *, Meagan Murphy, W. Patrick Monaghan, Cameron Cushenbery \\ University of North Florida, Brooks College of Health, Nurse Anesthesia Program, Jacksonville, Florida 32224 \\ *Corresponding author E-mail: n00625413@ospreys.unf.edu
}

\begin{abstract}
Background: Tape is the standard means of securing endotracheal tubes in the surgical environment to prevent accidental extubation. This study utilizes a mannequin model to examine the amount of force required to dislodge endotracheal tubes secured with four different varieties of commercially available tape and three different taping methods. This study also incorporates different angles of applied force and varying mannequin positions to simulate conditions often encountered in the operating room.

Methods: An airway trainer mannequin was intubated using a standard cuffed endotracheal tube and secured with one of four varieties of tape and one of three taping methods in randomly assigned order. The mannequin was placed in either the supine, lateral, or prone position. The endotracheal tube was then attached to a digital force meter and constant manual force applied in one of three planes (laterally to right, vertically, or laterally to left) until the cuff was removed from the trachea. Force measurements were recorded and analyzed. Results: Securing the endotracheal tube to both the maxillary and mandibular borders with Durapore ${ }^{\mathrm{TM}}$ silk tape held the endotracheal tube in the strongest, requiring the greatest force to dislodge it from the airway. Angle of force also showed statistical significance.

Conclusions: The amount of force required to dislodge endotracheal tubes is affected by tape type, taping method, and direction of force. Durapore $^{\mathrm{TM}}$ silk tape applied to both maxillary and mandibular borders was superior at holding the endotracheal tube in place when compared to other tape varieties and taping methods.
\end{abstract}

Keywords: Airway control, airway extubation, airway management, intubation, endotracheal intubation

\section{Introduction}

Approximately 20 million endotracheal tubes are placed annually in the U.S. (Lovett, Flaxman, Sturmann, \& Bijur, 2006). A large number of these intubations are performed in the surgical setting by anesthesia providers. The task of monitoring ventilatory status and maintaining a secure airway is one of the primary functions of anesthetists. Yet there is a lack of consensus on the ideal method of securing endotracheal tubes (ETTs) in conditions unique to the operating room (OR). The goal of our investigation was to determine which method of securing an endotracheal tube is most effective in preventing accidental dislodgement or extubation in the OR is setting.

Rates of unintentional extubation range from 1.6-21\% between anesthesia and intensive care environments (Lovett et al., 2006). According to the American Society of Anesthesiologists (ASA) Closed Claims Study, respiratory events constitute the largest source of adverse anesthesia outcomes, comprising 34\% of all claims. Of these adverse respiratory events, $7 \%$ were related to premature or unintentional tracheal extubation (Caplan, Posner, Ward, \& Cheney, 1990). Unintentional extubation represents a compromise in safety, with potential for ventilatory emergency, facial/oropharyngeal/tracheal trauma, bronchospasm, aspiration, dysrhythmias, cardiac arrest, brain injury, or death. Furthermore, over two thirds of repeat intubations following unintentional extubation involve difficulty (Lovett et al., 2006). So, it stands to reason that, as airway experts, anesthetists should be concerned not just with establishing a secure airway but also with ensuring it remains in place.

\section{Literature review}

The topic of ETT securement and preventing unintentional extubation has been examined in numerous research studies, with the majority of these studies focusing on the intensive care environment, respiratory therapy specialties, and preventative measures. To our knowledge there is yet to be any research studies incorporating different patient positions, as encountered in the operating room. In a 1997 laboratory report, Patel et al. examined extubation forces required to dislodge ETTs secured via seven different taping techniques with five varieties of tape. In this study, cloth tape (Kendall ${ }^{\mathrm{TM}}$ Curity ${ }^{\mathrm{TM}}$ ) held strongest, followed by waterproof Hy-Tape ${ }^{\circledR}$ and clear plastic tape $\left(3 \mathrm{M}^{\mathrm{TM}}\right.$ Transpore $\left.{ }^{\mathrm{TM}}\right)$. The most secure method of taping ETTs involved wrapping the ETT with two strips of tape, one securing the tube to the mandible and another to the maxilla. A significant limitation of this study was that it was performed using PVC pipe as a simulated airway and face to which the tape was secured. The size and rigid composition of the PVC pipe and absence of tracheal structures likely limits the applicability of this data to human subjects (Patel, Smith, Pinchak, \& Hancock, 1997).

In a landmark study in 2007, Carlson et al. used fresh unembalmed cadavers to test the holding force of cloth tape as opposed to four varieties of commercially manufactured endotracheal tube holders. The Thomas Tube Holder ${ }^{\mathrm{TM}}$ and cloth tape 
were shown to withstand extubation force the best among all methods tested (Carlson et al., 2007). Shimizu et al. compared three varieties of tape to two commercial ETT holders to determine which held ETTs most securely in an intubation mannequin (2011). They determined that long wide strips of conventional tape are superior to commercial ETT holders. In a similar study, Owen et al. compared amount of force required to dislodge ETTs placed in a cadaver and secured with either adhesive tape, cloth tape, or a commercial holder (2009). An additional factor measured in this study was the average time required to perform each technique. Results showed applying adhesive tape via the Lillehei method, familiar to many respiratory therapists, was the most time consuming but also the most secure. The Thomas Tube Holder ${ }^{\mathrm{TM}}$ was recommended as a quicker alternate method of ETT securement with effective resistance to extubation. Our study eliminated commercial ETT holders for three reasons: (1) fewer than 5\% of ETTs placed annually are secured with these devices, (2) these devices are typically not available in the OR environment, and (3) commercial ETT holders are cost-prohibitive for some facilities (Lovett et al., 2006).

\section{Study design \& methods}

As the review of literature portrays, there is a lack of cohesive evidence showing one method of endotracheal securement superior to others. Also no study specifically addresses ETT securement in the OR setting, incorporating position changes that are required for certain surgeries. In our bench study, we utilized a Laerdal ${ }^{\circledR}$ Airway Management Trainer ${ }^{\mathrm{TM}}$ intubation mannequin to simulate an adult patient. A wood frame measuring $26.5 \times 18 \times 22$ inches was constructed around the Laerdal ${ }^{\circledR}$ mannequin to ensure same angle of force application and the head was secured with blue foam and three inch Transpore ${ }^{\mathrm{TM}}$ clear tape to the wood frame to limit head movement and maintain neutral head alignment in varying positions and trial force application. We examined the effectiveness of securing an ETT with $1 / 2$ inch cloth tape (Kendall ${ }^{\mathrm{TM}}$ Curity ${ }^{\mathrm{TM}}$ ), waterproof pink tape (Hy-Tape $\left.{ }^{\circledR}\right)$, silk tape (3M $\mathrm{M}^{\mathrm{TM}}$ Durapore $\left.^{\mathrm{TM}}\right)$, and clear plastic tape (3M $\mathrm{M}^{\mathrm{TM}}$ Transpore $\left.{ }^{\mathrm{TM}}\right)$. Each brand of tape obtained was from the same manufacturer lot number. A standard cuffed $7.5 \mathrm{~mm}$ ETT was used for each trial (Cardinal Health, Inc.). New ETTs were utilized every tenth trial to limit accumulation of adhesive that could potentially alter the results. The mannequin face was also cleansed with an alcohol-based adhesive remover every tenth trial for the same purpose. After lightly coating the distal end of the endotracheal tube with artificial saliva (Biotene ${ }^{\circledR}$ Dry Mouth Moisturizing Liquid), a single researcher intubated the mannequin using a standard laryngoscope. Then, at a depth of 21 $\mathrm{cm}$, the ETT cuff was inflated with approximately $10 \mathrm{~mL}$ of air to a cuff pressure of $20 \mathrm{mmHg}$ as measured via manometer (Instrumentation Industries, NS-Series). The ETT was secured toward the right corner of the mouth using a randomly assigned tape and taping method, allocated via a computerized random number generator. Taping techniques included the following (Fig.1):

Method 1: A single piece of $1 / 2$ inch $x 12$ inch tape extended from one maxillary border, around the ETT once, and then across to the opposite maxilla.

Method 2: Same as method 1 with an additional piece of tape in the opposite direction across the maxilla.

Method 3: Same as method 1 with a second piece of tape wrapped around the ETT in the opposite direction and secured across the mandibular border.

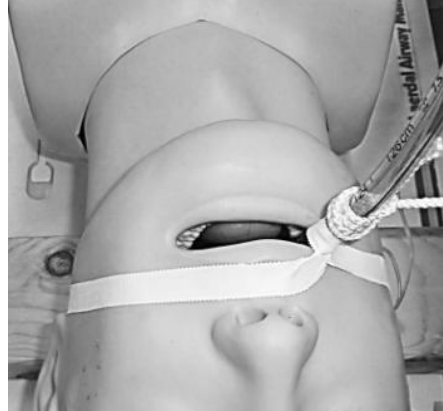

Taping Method 1

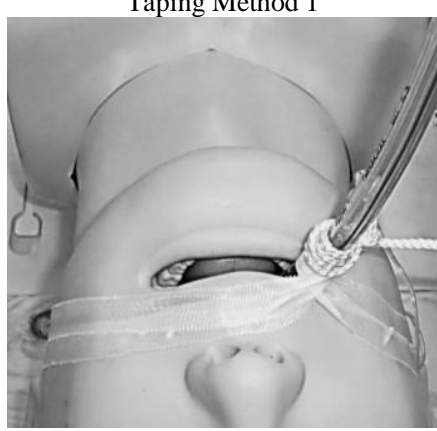

Taping Method 2

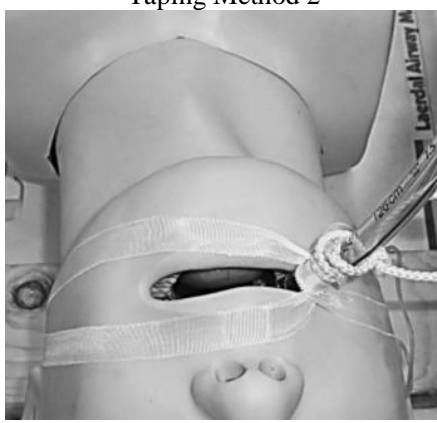

Taping Method 3

Fig. 1: Experimental taping methods

A digital force meter (HF-500) was attached to the distal end of the ETT using twine and constant manual force was applied by a single researcher in either a $0^{\circ}, 90^{\circ}$, or $180^{\circ}$ direction, correlating to planes perpendicular to the right, vertical, and perpendicular to the left (Fig. 2).

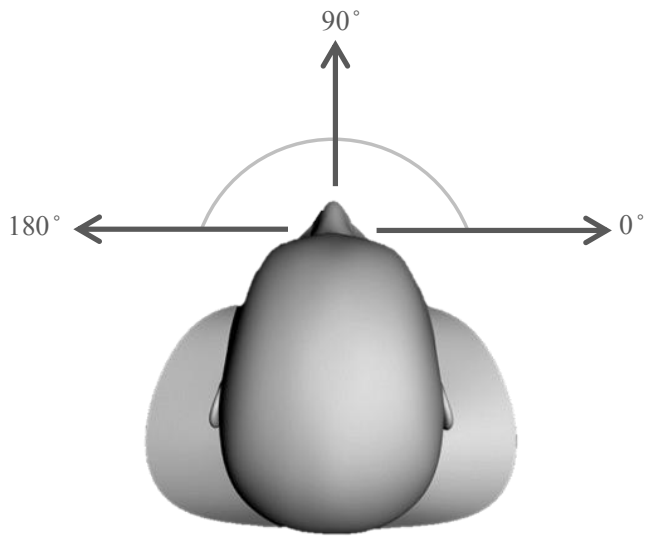

Fig. 2: Directions of force tested

A second researcher used a fiberoptic bronchoscope placed retrograde through the bronchus and into the trachea of the mannequin to visualize the cuff of the ETT as it was extracted. Herniation of the cuff through the vocal cords, simulating the loss of a secure airway, was the measured endpoint of extubation. Digital force meter measurements in Newtons $(\mathrm{N})$ were recorded at this determined endpoint. Trials were performed with the mannequin in supine, lateral, and prone positions, simulating positions used for a 
variety of surgical procedures. Five trials were conducted for each mannequin position, tape type, tape method, and direction of force $(n=540)$ in an attempt to derive which method of securing an endotracheal tube is most effective in preventing accidental dislodgement/extubation in the OR setting.

\section{Results}

Each variable, tape type, taping method, mannequin position, and angle of force, was examined via SAS software analysis to determine statistical significance. Tape type $(\mathrm{p}=0.0001)$, tape method $(\mathrm{p}=0.0001)$, and angle $(\mathrm{p}=0.0150)$ all demonstrated significance within a 95\% confidence interval. Mannequin position ( $\mathrm{p}=0.0937)$ did not yield statistical significance. Among the four tape varieties tested, Durapore ${ }^{\mathrm{TM}}$ silk tape resisted extubation forces the greatest $(100.27 \pm 23.38 \mathrm{~N})$, followed by Curity ${ }^{\mathrm{TM}}$ cloth tape $(67.87 \pm$ $13.04 \mathrm{~N})$, waterproof pink Hy-Tape ${ }^{\circledR}(57.15 \pm 11.71 \mathrm{~N})$, and Transpore ${ }^{\mathrm{TM}}$ clear tape $(35.44 \pm 8.30 \mathrm{~N})$ respectively (Table 1$)$.

Table 1: Tape Varieties and Force Required to Extubate

\begin{tabular}{|c|c|c|}
\hline Tape Type & Trials & Mean Extubation Force $(\mathrm{N})$ \\
\hline $3 \mathrm{M}^{\mathrm{TM}}$ Durapore ${ }^{\mathrm{TM}}$ Silk Tape & 135 & $100.27 \pm 23.38$ \\
\hline $\begin{array}{l}\text { Kendall }{ }^{\mathrm{TM}} \text { Curity }^{\mathrm{TM}} \text { Cloth } \\
\text { Tape }\end{array}$ & 135 & $67.87 \pm 13.04$ \\
\hline Hy-tape ${ }^{\circledR}$ & 135 & $57.15 \pm 11.71$ \\
\hline $\begin{array}{l}3 \mathrm{M}^{\mathrm{TM}} \text { Transpore } \\
\text { Tape }\end{array}$ & 135 & $35.44 \pm 8.30$ \\
\hline
\end{tabular}

Comparing taping methods, method 3 of taping the ETT to both the maxillary and mandibular borders held the ETT most securely in place $(76.25 \pm 32.09 \mathrm{~N})$ followed by taping method $2(69.15 \pm$ $23.21 \mathrm{~N})$, and method $1(50.15 \pm 20.15 \mathrm{~N})$ respectively (Table 2$)$.

Table 2: Taping Method and Force Required to Extubate

\begin{tabular}{ll}
\hline Taping Method & Mean Extubation Force $(\mathrm{N})$ \\
\hline $\begin{array}{l}\text { Method 1 - single tape piece of tape, } \\
\text { maxilla }\end{array}$ & $50.15 \pm 20.15$ \\
$\begin{array}{l}\text { Method 2 - two tape pieces, maxilla } \\
\text { Method 3 - two tape pieces, maxilla and }\end{array}$ & $69.15 \pm 23.21$ \\
mandible & $76.25 \pm 32.09$ \\
\hline
\end{tabular}

A higher force was needed to extubate the mannequin when pulling the ETT perpendicularly to the right (angle $\left.0^{\circ}\right)(66.17 \pm 28.72$ $\mathrm{N})$ as compared to pulling the ETT vertically $\left(90^{\circ}\right)(66.03 \pm 30.17$ $\mathrm{N})$ or perpendicularly to the left $\left(180^{\circ}\right)(63.36 \pm 24.50 \mathrm{~N}$, $\mathrm{p}=0.0150)($ Table 3$)$.

Table 3: Angle of Applied Force and Force Required to Extubate

\begin{tabular}{ll}
\hline Angle of Force & Mean Extubation Force $(\mathrm{N})$ \\
\hline Angle $0^{\circ}$ - Right & $66.17 \pm 28.72$ \\
Angle $90^{\circ}$ - Vertical & $66.03 \pm 30.17$ \\
Angle $180^{\circ}$ - Left & $63.36 \pm 24.50$ \\
\hline
\end{tabular}

A three by four factorial was analyzed using SPSS software to evaluate the statistical significance of each factor independently of the others (Fig. 3). Use of Durapore ${ }^{\mathrm{TM}}$ silk tape with taping method 3 provided the strongest hold of the ETT, requiring the most force to extubate $(122.70 \mathrm{~N})$. Progressive weakening of this resistance was noted with taping methods $2(101.17 \mathrm{~N})$ and $1(76.95$ N) $(\mathrm{p}<0.0001)$. A similar trend was noted with Curity ${ }^{\mathrm{TM}}$ cloth tape, with taping method 3 resisting extubation forces more (78.34 $\mathrm{N})$ than method $2(70.70 \mathrm{~N})$ or method $1(54.68 \mathrm{~N})(\mathrm{p}<0.0001)$. It stands to reason that more pieces of tape, allowing for more adhesive surface area, would lend improved holding power between methods 1 (single piece of tape) and methods 2 and 3 (both using two pieces of tape). But the enhanced adhesive strength from method 2 to method 3 seems to imply improved ETT securement based on tape placement. Differences between taping methods 2 and 3 was less distinct and statistically insignificant with HyTape ${ }^{\circledR}(\mathrm{p}=0.1556)$ and Transpore ${ }^{\mathrm{TM}}$ tape $(\mathrm{p}=0.0750)$. The authors observed the tendency of Hy-Tape ${ }^{\circledR}$ and Transpore ${ }^{\mathrm{TM}}$ tape to fracture as opposed to becoming detached from the mannequin facial surface. This tendency to fracture could explain the improvement between method 1 and methods 2 and 3, seeing it is harder to break two pieces of tape than one. It could also explain the lack of statistical difference for both the Hy-Tape ${ }^{\circledR}$ and Transpore ${ }^{\mathrm{TM}}$ tapes between methods 2 and 3 because both taping methods utilize two pieces of tape.

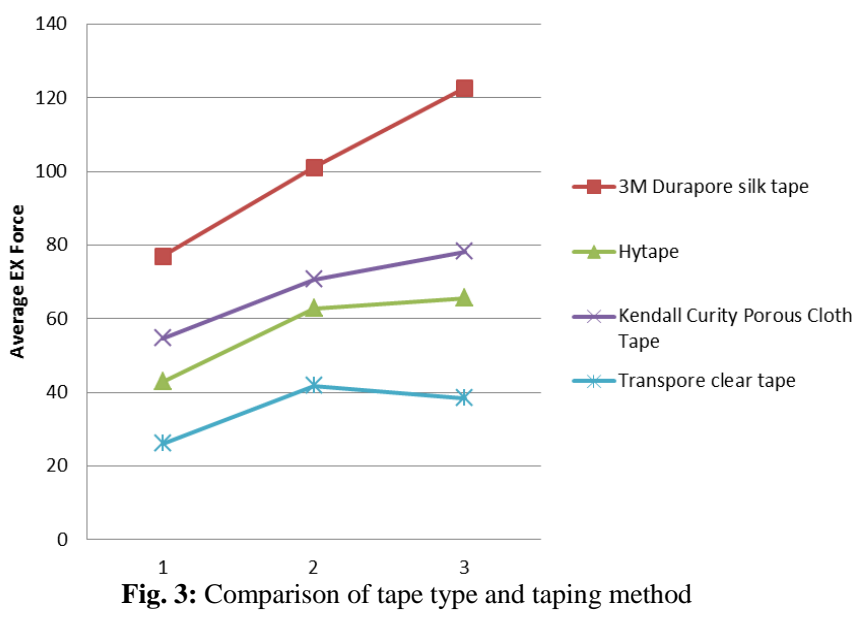

ETTs secured with silk tape (3M $\mathrm{M}^{\mathrm{TM}}$ Durapore $\left.{ }^{\mathrm{TM}}\right)$ employing method 3 proved to be superior to any other tape and method combination.

\section{Discussion}

Anesthesia providers are expected to be experts at airway management and it is essential that they be knowledgeable and skillful at securing advanced airway devices. Failure to appropriately secure ETTs could result in airway compromise and potential catastrophe. Of tape types commonly found in the clinical environment, silk tape holds ETTs most securely in a variety of patient positions, angles of force, and taping methods. Additional pieces of tape increase resistance to extubation forces, most likely due to increased adhesive surface area. In fact, other studies have reported similar findings with longer, thicker pieces of tape (Patel et al. 1997, Shimizu et al. 2011). Our finding that securing ETTs to both the maxillary and mandibular borders is superior to other taping methods is also supported by previous research (Patel et al., 1997). With reimbursement challenges and skyrocketing medical costs in modern healthcare, medical providers must take financial expense into account in daily practice. Cost analyses for each of the four varieties of tape tested are listed in Table 4. Of the four varieties of tape tested in this study, Durapore ${ }^{\mathrm{TM}}$ silk tape was not only the most effective at preventing extubation, it was also cost the least per unit.

Table 4: Cost Comparison of Tape Types

\begin{tabular}{|c|c|c|}
\hline Tape Type & Cost per Inch & Cost per Patient ${ }^{\mathrm{a}}$ \\
\hline Hy-tape $\AA$ & $\$ 0.058$ & $\$ 1.39$ \\
\hline $\begin{array}{l}\text { Kendall }{ }^{\mathrm{TM}} \text { Curity }{ }^{\mathrm{TM}} \text { Cloth } \\
\text { Tape }\end{array}$ & $\$ 0.0083$ & $\$ 0.20$ \\
\hline $\begin{array}{l}\text { 3M } \mathrm{M}^{\mathrm{TM}} \text { Transpore } \\
\text { Tape }\end{array}$ & $\$ 0.0015$ & $\$ 0.04$ \\
\hline $\begin{array}{l}3 \mathrm{M}^{\mathrm{TM}} \text { Durapore }{ }^{\mathrm{TM}} \text { Silk Tape } \\
{ }^{\mathrm{a}} \text { Assuming two } 1 / 2 \times 12 \text { inch } \\
\text { mated from retail cost obtain }\end{array}$ & $\begin{array}{l}\$ 0.0011 \\
\text { es of tape per } \\
\text { rom Amazon. }\end{array}$ & $\begin{array}{l}\$ 0.03 \\
\text { ient. Price esti- }\end{array}$ \\
\hline
\end{tabular}

\section{Limitations}

Use of a Laerdal ${ }^{\circledR}$ Airway Management Trainer ${ }^{\mathrm{TM}}$ only simulates human airway and skin structure. Differences in contour, surface texture and plasticity likely exist. Human skin has hair, oils, and irregularities in texture that may alter the adhesive quality of tape. Furthermore, excess secretions, saliva, or blood encountered in the clinical setting may reduce the adhesive quality of tape and poten- 
tially effect resistance to extubation. How these anatomical and physiologic differences would affect results is unclear. It is also unclear how much resistance to extubation is considered safe or adequate for the OR environment. Further correlation is needed to assess how extubation forces encountered in our study relate to forces commonly seen in the clinical setting. Constant force was measured in this study for consistency of measurement as opposed to dynamic jerking. Jerking motions may be more of a risk in the OR; however accurate measuring of these forces presents a challenge.

\section{Conclusion}

Limited data exists on the ideal method of endotracheal tube securement in the operating room environment. With millions of endotracheal tubes being secured annually in the OR with no consistent evidence to support an ideal method of securement in this setting, more data is needed to make a consensus decision The goal of this proposed bench study was to fill a gap in evidentiary research and add to generalizable knowledge in the field of anesthesia. This topic holds implications for patient safety in limiting the potential for unintentional extubation and subsequent adverse pulmonary events.

\section{References}

[1] Caplan, R. A., Posner, K. L., Ward, R. J., \& Cheney, F. W. (1990). Adverse respiratory events in anesthesia: A closed claims analysis. Anesthesiology, 72, 828-833. Retrieved from http://journals.lww.com/anesthesiology/.

[2] Carlson, J., Mayrose, J., Krause, R., \& Jehle, D. (2007). Extubation force: Tape versus endotracheal tube holders. Annals of Emergency Medicine, 50, 686-691. Doi: 10.1016/ j.annemergmed.2007.05.013.

[3] Lovett, P., Flaxman, A., Sturmann, K., \& Bijur, P. (2006). The insecure airway: A comparison of knots and commercial devices for securing endotracheal tubes. BMC Emergency Medicine, 6, 1-7. Doi: 10.1186/1471-227X-6-7.

[4] Owen, R., Castle, N., Hann, H., Reeves, D., Naidoo, R., \& Naidoo, S. (2009). Extubation force of adhesive tape, non-adhesive tape and commercial endotracheal tube holder. Resuscitation, 80, 1296-1300. doi:10.1016/j.resuscitation.2009.08.007.

[5] Patel, N., Smith, C., Pinchak, A., \& Hancock, D. (1997). Taping methods and tape types for securing oral endotracheal tubes. Canadian Journal of Anesthesia, 44, 330-336. Retrieved from http://www.springer.com/medicine/anesthesiology/journal/12630.

[6] Shimizu, T., Mizutani, T., Yamashita, S., Hagiya, K., \& Tanaka, M. (2011). Endotracheal tube extubation force: Adhesive tape versus endotracheal tube holder. Respiratory Care, 56, 1825-1829. doi: $10.4187 /$ respcare.00954. 